\title{
Analisis pergeseran sektor unggulan Kabupaten Tanjung Jabung Barat
}

\author{
Alex Salenko Munthe*; Zulgani; Hardiani \\ Prodi Ekonomi Pembangunan Fak. Ekonomi dan Bisnis, Universitas Jambi \\ *E-mail korespondensi: alexsalenkomunthe@rocketmail.com
}

\begin{abstract}
The purpose of this research is to analyze the shifts that occur to the three leading sectors in the Regency of West Tanjung Jabung and to find out how much contribution from the three leading sectors to the economic growth during the period 2011-2015. The data collection method used in this research is secondary data analysis which is collecting data through the material of the library. From based on the result of data analysis, the result of the shift of the three leading sectors of the economy Tanjung Jabung District West during 2011-2015 using shift-share analysis changed at the national level (Ns) of $3,851,361.79$, with a differential shift $(D)$ value of $-34,748.82$ and proportional shift $(P)$ value of $-295,710.45$, where the value of shifting the three leading sectors experienced development in the period 2011-2015 amounted to 3,520,902.92. The three leading sectors are classified into the analysis of Typology Klassen to determine the value of its contribution to the growth rate of the region, where the mining and quarrying sectors become the first quadrant, the manufacturing sector becomes the second quadrant, and then the agriculture, forestry, and fishery sectors become the third quadrant.
\end{abstract}

Keywords: Leading sector, Shift-share, Typology klassen, Economic growth.

\begin{abstract}
Abstrak
Tujuan penelitian kali ini adalah untuk menganalisis pergeseran yang terjadi terhadap ketiga sektor unggulan yang ada di Kabupaten Tanjung Jabung Barat dan untuk mengetahui seberapa besar kontribusi dari ketiga sektor unggulan tersebut terhadap pertumbuhan ekonomi daerah selama periode 2011-2015. Metode yang digunakan dalam penelitian ini adalah analisis data sekunder melalui bahan-bahan kepustakaan. Berdasarkan hasil analisis data, pergeseran ketiga sektor unggulan ekonomi Kabupaten Tanjung Jabung Barat tahun 2011-2015 dengan menggunakan analisis Shift-Share mengalami perubahan pada tingkat nasional (Ns) sebesar 3,851,361.79, dengan nilai differential shift (D) sebesar -34,748.82 dan nilai proportional shift (P) sebesar 295,710.45, dimana nilai pergeseran ketiga sektor unggulan tersebut mengalami perkembangan dalam kurun waktu 2011-2015 sebesar 3,520,902.92. Ketiga sektor unggulan tersebut diklasifikasikan kedalam analisis Tipologi Klassen guna mengetahui nilai kontribusinya terhadap tingkat pertumbuhan daerah, dimana sektor pertambangan dan penggalian menjadi kuadran I, sektor industri pengolahan menjadi kuadran II, dan sektor pertanian, kehutanan dan perikanan menjadi kuadran III.
\end{abstract}

Kata kunci: Sektor Unggulan, Shift-Share, Tipologi Klassen, Pertumbuhan Ekonomi.

\section{PENDAHULUAN}

Menurut Tan (2013), pembangunan merupakan suatu proses menuju perubahan yang lebih baik melalui upaya-upaya yang dilakukan dengan sadar dan terencana. Konteksnya juga dapat dilihat dari sisi ekonomi dimana pembangunan tersebut berorientasi pada peningkatkan kesejahteraan masyarakat, penurunan kemiskinan, 
pengangguran, ketimpangan, tenaga kerja dan kestabilan tingkat inflasi. Sasaran utama dalam pembangunan nasional adalah meningkatkan pertumbuhan ekonomi serta pemerataan hasil-hasilnya dan juga ditujukan bagi pemantapan stabilitas nasional. Hal tersebut sangat ditentukan keadaan pembangunan secara kedaerahan. Menurut Sukirno (2006), pembangunan negara ditinjau dari sudut ruang atau wilayahnya dan dalam konteks ini istilah yang paling tepat digunakan adalah pembangunan wilayah dan strategi pembangunan daerah dimaksudkan sebagai suatu langkah untuk melengkapi strategi makro dan sektoral dari pembangunan nasional. Sirojuzilam dan Mahalli (2010) menyatakan bahwa pada dasarnya pembangunan daerah berkenaan dengan tingkat dan perubahan selama kurun waktu tertentu suatu set variabel-variabel seperti variabel produksi, penduduk, tenaga kerja, angkatan kerja, rasio modal dan imbalan bagi faktor faktor produksi dalam daerah yang di batasi secara jelas

Menurut Arsyad (1999), pembangunan ekonomi daerah merupakan suatu proses yang dimana pemerintah daerah dan masyarakatnya mengelola sumber daya yang ada dan membentuk suatu pola kemitraan antara pemerintah daerah dan sektor swasta untuk menciptakan suatu lapangan kerja baru serta merangsang perkembangan kegiatan ekonomi dalam wilayah tersebut. Kriteria-kriteria tersebut haruslah sesuai dengan kondisi potensi daerah serta aspirasi-aspirasi dari setiap masyarakat yang tumbuh dan berkembang di daerah masing-masing agar dapat merangsang tingkat pertumbuhan ekonomi daerah tersebut menuju ke arah yang lebih baik. Dalam strategi pembangunan wilayah aspek-aspek pokok yang penting dipecahkan adalah di daerah-daerah mana serangkaian pembangunan selayaknya dijalankan. Munir (2002) menyatakan bahwa perbedaan kondisi daerah akan membawa implikasi bahwa corak pembangunan yang diterapkan di setiap daerah akan berbeda pula. Peniruan mentah-mentah terhadap pola kebijaksanaan yang pernah diterapkan dan berhasil pada suatu daerah, belum tentu memberi manfaat yang sama bagi daerah yang lain.

Dalam rangka pembangunan manusia seutuhnya dan pembangunan seluruhnya masayarakat Indonesia, pembangunan daerah perlu dipacu secara bertahap. Untuk menjamin agar pembangunan daerah dapat memberikan sumbangan yang maksimal dalam keseluruhan usaha pembangunan nasional haruslah dilakukan kordinasi yang baik antara keduanya. Hal ini berarti bahwa pemerintah daerah harus mempertimbangkan berbagai rencana pemerintah pusat maupun di daerah lain. Kuncoro (2000) menegaskan bahwa pertumbuhan ekonomi setiap daerah akan sangat bervariasi sesuai dengan potensi ekonomi yang dimiliki oleh daerah tersebut maka pertumbuhan ekonomi yang tinggi diharapkan akan meningkatkan kesejahteraan masyarakat.

Salah satu tolak ukur dalam kesuksesan pembangunan ekonomi daerah tersebut ialah meningkatnya pertumbuhan ekonomi daerah yang ditandai dengan stabilnya tingkat pembangunan ekonomi daerah terhadap pertumbuhan ekonomi daerah yang tinggi dan juga pararel terhadap tingkat pertumbuhan ekonomi nasional agar dapat mencapai tujuantujuan lainnya dari pembangunan ekonomi daerah tersebut. Pertumbuhan ekonomi yang tinggi diharapkan akan meningkatkan kesejahteraan masyarakat. Menurut Tarigan (2005), tingkat pertumbuhan ekonomi daerah tersebut dapat diukur melalui laju pertumbuhan ekonomi daerah yang ditentukan oleh besarnya peningkatan ekspor dari wilayah produksi ke wilayah lainnya melalui kontribusi sektor-sektor ekonomi yang ada dan berkembang di daerah. Namun hanya kontribusi dari sektor-sektor unggulan yang mampu mendorong tingkat pertumbuhan ekonomi daerah tersebut. Keadaan tersebut diharapkan mampu mengangkat kesenjangan pendapatan daerah dan juga mampu mensejahterakan masyarakat melalui kontribusi sektor-sektor unggulan. Adisasmita (2008) juga menambahkan bahwa semakin besar ekspor suatu wilayah ke wilayah lain akan semakin maju pertumbuhanan wilayah tersebut, dan demikian sebaliknya. Setiap perubahan yang terjadi pada sektor-sektor unggulan tersebut akan menimbulkan efek ganda (multiplier effect) dalam perekonomian daerah. 
Melalui sumber data yang di seminarkan oleh Alamsyah (2016), pada tahun 2011, sektor pertambangan dan penggalian menjadi sektor unggulan pertama yang menyumbang pendapatan daerah sebesar 9,525,161.45 (jutaan rupiah) atau 45.81 persen dari total PDRB Kabupaten Tanjung Jabung Barat tahun 2011 sebesar 20,794,458.62 (jutaan rupiah). Diikuti dengan sektor industri pengolahan pada urutan kedua dan sektor pertanian, kehutanan dan perikanan diurutan ketiga yang masing-masing menyumbang pendapatan daerah sebesar 4,293,757.57 (jutaan rupiah) atau 20.64 persen dan 3,945,664.69 (jutaan rupiah) atau 18.97 persen. Dan dalam kurun waktu lima tahun yakni pada tahun 2015, PDRB Kabupaten Tanjung Jabung Barat mengalami penikatan yang cukup signifikan sebesar 25,446,121.48 (jutaan rupiah) atau berkembang sebesar 22.58 persen. Ketiga sektor unggulan tersebut memiliki peran penting dalam peningkatan pertumbuhan PDRB Kabupaten Tanjung Jabung Barat periode 2011-2015.

Berdasarkan ulasan perekonomian yang ada di atas, penulis mencoba untuk menganalisis sampai seberapa jauh peran ketiga sektor unggulan tersebut terhadap pertumbuhan ekonomi di Kabupaten Tanjung Jabung Barat. Maka oleh dari karena itu, penulis tertarik dalam melakukan sebuah penelitian yang berjudul "Analisis pergeseran sektor unggulan kabupaten tanjung jabung barat".

\section{METODE}

\section{Jenis dan sumber data}

Jenis data yang digunakan dalam penelitian ini ialah data sekunder kurun waktu ( time series) yakni data PDRB Kabupaten Tanjung Jabung Barat atas dasar harga konstan menurut lapangan usaha selama periode 2011-2015. Sumber data yang digunakan dalam penelitian ini bersumber dari instansi-instansi terkait pemerintahan dalam pengembangan pertumbuhan ekonomi yakni Badan Pusat Statistik (BPS) Kabupaten Tanjung Jabung Barat dan BPS Provinsi Jambi, meliputi : 1).Badan Pusat Statistik Provinsi Jambi menurut PDRB kabupaten/kota tahun 2010-2016; 2).Badan Pusat Statistik Kabupaten Tanjung Jabung Barat tahun 2016; 3).Tanjung Jabung Barat dalam angka 2012-2016; 4).Provinsi Jambi dalam angka 2016; 5).Buku buku atau literatur kepustakaan yang terkait; 6).Sumber-sumber ilmiah dari internet.

\section{Analisis data}

Metode analisis data yang digunakan ialah metode analisis kuantitatif. Data kuantitatif diperlukan untuk mengukur pergeseran sektor-sektor unggulan dan kontribusi sektor-sektor unggulan itu sendiri terhadap tingkat pendapatan yang berpengaruh terhadap pertumbuhan ekonomi Kabupaten Tanjung Jabung Barat periode 2011-2015.

Analisis shift share digunakan untuk menghitung nilai pergeseran yang terjadi terhadap ketiga sektor unggulan Kabupaten Tanjung Jabung Barat tahun 2011-2015 yaitu sektor pertanian, kehutanan dan kelautan, sektor pertambangan dan penggalian, dan sektor industri pengolahan. Penghitungan tersebut dapat dilihat pada notasi aljabar atas komponen komponen shift share berikut :

$$
\begin{aligned}
& \Delta \mathrm{E}_{\mathrm{r}, \mathrm{i}}=(\mathrm{Ns}+\mathrm{Pr}+\mathrm{Dr}) \\
& \text { Ns } \mathrm{i,t}=\mathrm{E}_{\mathrm{r}, \mathrm{i}, \mathrm{t}-\mathrm{n}}\left(\mathrm{E}_{\mathrm{N}, \mathrm{t}} / \mathrm{E}_{\mathrm{N}, \mathrm{t}-\mathrm{n}}\right)-\mathrm{E}_{\mathrm{r}, \mathrm{i}, \mathrm{t}-\mathrm{n}} \\
& \mathrm{P}_{\mathrm{r}, \mathrm{i}, \mathrm{t}}=\left\{\left(\mathrm{E}_{\mathrm{N}, \mathrm{i}, \mathrm{t}} / \mathrm{E}_{\mathrm{N}, \mathrm{i}, \mathrm{t}-\mathrm{n}}\right)-\left(\mathrm{E}_{\mathrm{N}, \mathrm{t}} / \mathrm{E}_{\mathrm{N}, \mathrm{t}-\mathrm{n}}\right)\right\} \mathrm{x}_{\mathrm{r}, \mathrm{i}, \mathrm{t}-\mathrm{n}} \\
& \left.D_{r, i, t}=\left\{E_{r, i, t}-\left(E_{N, i, t} / E_{N, i, t-n}\right) E_{r, i, t-n}\right)\right\}
\end{aligned}
$$

Dimana:

$\Delta \quad=$ Pertambahan nilai angka akhir (tahun $\mathrm{t}$ ) dikurangi angka awal (tahun $\mathrm{t}-\mathrm{n}$ )

$\mathrm{N} \quad=$ wilayah yang lebih tinggi jenjangnya ( Provinsi Jambi )

$\mathrm{r} \quad=$ wilayah analisis (Kab. Tanjung Jabung Barat) 


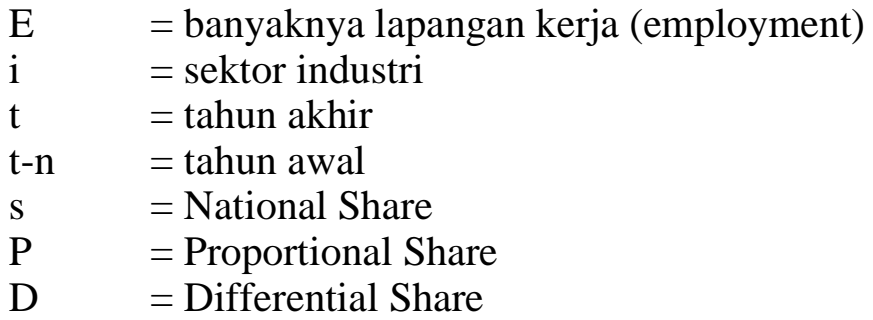

Analisis lain yang diperlukan untuk mencari besaran kontribusi ketiga sektor unggulan tersebut bagi pertumbuhan ekonomi Kabupaten Tanjung Jabung Barat 20112015 yakni dengan menggunakan alat analisis tipologi klassen. Penghitungan tersebut menggunakan data PDRB sektor-sektor ekonomi yang sama di Provinsi Jambi sebagai bahan acuan perbandingannya, guna mencari nilai rata-rata pertumbuhan dan rata-rata kontribusi pertumbuhan tersebut. Penghitungan tersebut dapat dijabarkan sebagai berikut:

$$
\begin{array}{rl}
g_{\mathrm{i}}=\frac{\mathrm{PDRB}_{\mathrm{r}, \mathrm{i}, \mathrm{t}}-\mathrm{PDRB}_{\mathrm{r}, \mathrm{i}, \mathrm{t}-\mathrm{n}}}{\frac{\mathrm{PDRB}_{\mathrm{r}, \mathrm{i}, \mathrm{t}-\mathrm{n}}}{4}} \times 100 & \mathrm{~g}=\frac{\mathrm{PDRB}_{\mathrm{N}, \mathrm{i}, \mathrm{t}}-\mathrm{PDRB}_{\mathrm{N}, \mathrm{i}, \mathrm{t}-\mathrm{n}}}{\frac{\mathrm{PDRB}_{\mathrm{N}, \mathrm{i}, \mathrm{t}-\mathrm{n}}}{4}} \times 100 \\
\mathrm{~s}_{\mathrm{i}}=\frac{\mathrm{PDRB}_{\mathrm{r}, \mathrm{i}, \mathrm{t}}+\mathrm{PDRB}_{\mathrm{r}, \mathrm{i}, \mathrm{t}-\mathrm{n}}}{\mathrm{EPDRB}_{\mathrm{r}, \mathrm{t}}+\mathrm{EPDRB}_{\mathrm{r}, \mathrm{t}-\mathrm{n}}} \times 100 & \mathrm{~s}=\frac{\mathrm{PDRB}_{\mathrm{N}, \mathrm{i}, \mathrm{t}}+\mathrm{PDRB}_{\mathrm{N}, \mathrm{i}, \mathrm{t}-\mathrm{n}}}{\mathrm{EPDRB}_{\mathrm{N}, \mathrm{t}}+\mathrm{PPDRB}_{\mathrm{N}, \mathrm{t}-\mathrm{n}}} \mathrm{P} 100
\end{array}
$$

Dimana:

$\mathrm{g}_{\mathrm{i}}$

$=$ Rata-rata pertumbuhan PDRB sektor unggulan Kabupaten Tanjung Jabung Barat

g = Rata-rata pertumbuhan PDRB sektor yang sama Provinsi Jambi

$\mathrm{S}_{\mathrm{i}} \quad=$ Rata-rata kontribusi sektor unggulan Kabupaten Tanjung Jabung Barat

s $\quad=$ Rata-rata kontribusi sektor yang sama Provinsi Jambi

PDRB $_{r, i, t} \quad=$ PDRB sektor unggulan Kabupaten Tanjung Jabung Barat tahun akhir

$\mathrm{PDRB}_{\mathrm{r}, \mathrm{i}, \mathrm{t}-\mathrm{n}} \quad=$ PDRB sektor unggulan Kabupaten Tanjung Jabung Barat tahun awal

$\mathrm{PDRB}_{\mathrm{N}, \mathrm{i}, \mathrm{t}} \quad=$ PDRB sektor yang sama Provinsi Jambi tahun akhir

$\mathrm{PDRB}_{\mathrm{N}, \mathrm{i}, \mathrm{t}-\mathrm{n}} \quad=$ PDRB sektor yang sama Provinsi Jambi tahun awal

E PDRB $_{r, t} \quad=$ Total PDRB Kabupaten Tanjung Jabung Barat tahun akhir

E PDRB $_{r, t-n} \quad=$ Total PDRB Kabupaten Tanjung Jabung Barat tahun awal

E PDRB $_{r, t}=$ Total PDRB Provinsi Jambi tahun akhir

$\mathrm{E} \mathrm{PDRB}_{\mathrm{r}, \mathrm{t}-\mathrm{n}}=$ Total PDRB Provinsi Jambi tahun awal

Setelah melakukan penghitungan terhadap rata-rata pertumbuhan dan rata-rata kontribusi sektor-sektor unggulan tersebut dengan menggunakan persamaan rumus di atas yang juga telah dikelompokkan melalui penghitungan tersebut, maka hasil dari penghitungan pengelompokan sektor-sektor unggulan Kabupaten Tanjung Jabung Barat 2011-2015 dapat diklasifikasikan dalam tabel tipologi klassen di bawah ini:

\begin{tabular}{|c|c|c|}
\hline \multirow{2}{*}{$\begin{array}{c}\text { Kontribusi } \\
\text { sektoral }\end{array}$} & \multicolumn{2}{|c|}{ Pertumbuhan sektoral } \\
\hline & $g_{i} \geq g$ & $\mathrm{~g}_{\mathrm{i}} \leq \mathrm{g}$ \\
\hline $\mathrm{S}_{\mathrm{i}} \geq \mathrm{S}$ & Sektor maju dan tumbuh pesat & Sektor maju tapi tertekan \\
\hline $\mathrm{S}_{\mathrm{i}} \leq \mathrm{S}$ & $\begin{array}{l}\text { Sektor potensial atau masih dapat } \\
\text { berkembang pesat }\end{array}$ & Sektor relatif tertinggal \\
\hline
\end{tabular}

Tabel 1. Klasifikasi ekonomi menurut tipologi Klassen

Sumber: Chaniago Junaidi (blog), 2010 
Dimana:

Kuadran $\mathrm{I} \quad=$ Sektor maju dan tumbuh pesat $\left(\mathrm{g}_{\mathrm{i}} \geq \mathrm{g}\right.$ dan $\left.\mathrm{s}_{\mathrm{i}} \geq \mathrm{s}\right)$

Kuadran II $=$ Sektor maju tapi tertekan $\left(\mathrm{g}_{\mathrm{i}} \geq \mathrm{g}\right.$ dan $\left.\mathrm{s}_{\mathrm{i}} \geq \mathrm{s}\right)$

Kuadran III $=$ Sektor potensial $\left(\mathrm{g}_{\mathrm{i}} \geq \mathrm{g}_{\text {dan }} \mathrm{s}_{\mathrm{i}} \leq \mathrm{s}\right)$

Kuadran IV $=$ Sektor relatif tertinggal $\left(\mathrm{g}_{\mathrm{i}} \leq \mathrm{g}\right.$ dan $\left.\mathrm{s}_{\mathrm{i}} \leq \mathrm{s}\right)$

\section{HASIL DAN PEMBAHASAN}

\section{Pergeseran ketiga sektor unggulan Kabupaten Tanjung Jabung Barat}

Kabupaten Tanjung Jabung Barat memiliki tiga sektor ekonomi unggulan. Sektorsektor tersebut ialah sektor pertanian, kehutanan dan perikanan, sektor pertambangan dan penggalian, dan terakhir sektor industri pengolahan. Ketiga sektor unggulan tersebut berpengaruh cukup besar bagi perkembangan ekonomi daerah. Tiap tahunnya sektorsektor unggulan tersebut mengalami pergeseran yang juga berpengaruh terhadap tingkat pertumbuhan ekonomi Kabupaten Tanjung Jabung Barat. Melalui analisis shift share atas dasar tiga komponen yang ada, dapat ditentukanlah arah pergeseran yang terjadi terhadap ketiga sektor unggulan Kabupaten Tanjung Jabung Barat 2011-2015 dengan PDRB sektor-sektor yang sama di Provinsi Jambi pada tahun 2011-2015 sebagai bahan acuan perbandingannya. PDRB dari ketiga sektor tersebut dapat dilihat pada tabel berikut:

Tabel 2. PDRB sektor pertanian, kehutanan dan perikanan, sektor pertambangan dan penggalian, dan sektor industri pengolahan Kabupaten Tanjung Jabung Barat dan Provinsi Jambi tahun 2011-2015

\begin{tabular}{|c|c|c|c|c|}
\hline \multirow[t]{3}{*}{ Sektor } & \multicolumn{2}{|c|}{$\begin{array}{c}\text { PDRB Kabupaten } \\
\text { Tanjung Jabung Barat } \\
\text { (Jutaan Rupiah) }\end{array}$} & \multicolumn{2}{|c|}{$\begin{array}{c}\text { PDRB } \\
\text { Provinsi Jambi } \\
\text { (Milyar Rupiah) }\end{array}$} \\
\hline & 2011 & 2015 & 2011 & 2015 \\
\hline & $E_{r, i, t-n}$ & $E_{r, i, t}$ & $\mathbf{E}_{\mathrm{N}, \mathrm{i}, \mathrm{t}-\mathrm{n}}$ & $E_{N, i, t}$ \\
\hline $\begin{array}{l}\text { Pertanian, Kehutanan, dan } \\
\text { Perikanan }\end{array}$ & $3,945,664.69$ & $5,431,857.89$ & $24,744.9$ & $32,815.9$ \\
\hline Pertambangan dan Penggalian & $9,525,161.45$ & $10,826,626.48$ & $27,265.3$ & $30,879.9$ \\
\hline Industri Pengolahan & $4,293,757.57$ & $5,027,002.18$ & $11,217.1$ & $13,948.8$ \\
\hline Jumlah & $17,491,583.7$ & $21,285,486,6$ & $63,257.3$ & $77,644.6$ \\
\hline
\end{tabular}

Sumber: BPS Provinsi Jambi, 2016 (data diolah)

Berdasarkan dari hasil data PDRB sektor unggulan Kabupaten Tanjung Jabung Barat 2011-2015 yakni sektor pertanian, kehutanan dan perikanan, sektor pertambangan dan penggalian, dan sektor industri pengolahan dengan bahan acuan perbandingan sektor-sektor yang sama di Provinsi Jambi pada periode 2011-2015 di atas, maka di bawah ini dapat dilihat hasil dari penghitungan pergeseran ketiga sektor unggulan tersebut melalui tiga komponen shift-share, yakni :

Tabel 3. Pergeseran ketiga sektor unggulan Kabupaten Tanjung Jabung Barat Tahun 2011-2015

\begin{tabular}{lccc}
\hline \multirow{2}{*}{ Sektor } & $\begin{array}{c}\text { National } \\
\text { Share (Ns) }\end{array}$ & $\begin{array}{c}\text { Proportional } \\
\text { Shift (P) }\end{array}$ & $\begin{array}{c}\text { Differential } \\
\text { Shift (D) }\end{array}$ \\
\cline { 2 - 4 } & $\mathbf{N s}_{\mathbf{i}, \mathbf{t}}$ & $\mathbf{P}_{\mathbf{r}, \mathbf{i}, \mathbf{t}}$ & $\mathbf{D}_{\mathbf{r}, \mathbf{i}, \mathbf{t}}$ \\
\hline pertanian, kehutanan, dan perikanan & $855,420.1$ & $431,261.151$ & $199,511.94$ \\
pertambangan dan penggalian & $2,065,055.05$ & $-802,971.11$ & $39,381.18$ \\
industri pengolahan & $930,886.64$ & $75,999.509$ & $-273,641.54$ \\
\hline \multicolumn{1}{c}{ Jumlah } & $3,851,361.79$ & $-295,710.45$ & $-34,748.42$ \\
\hline
\end{tabular}

Sumber: Data diolah, 2018 
Berdasarkan penghitungan nilai shift share ketiga sektor unggulan Kabupaten Tanjung Jabung Barat selama periode 2011-2015 menunjukkan bahwa pergeseran yang dipengaruhi oleh komponen national share (Ns), ketiga sektor unggulan tersebut berada di angka 3,851,361.79 (jutaan rupiah). Hal ini mengindikasikan bahwa ketiga sektor unggulan tersebut sangat berpengaruh terhadap perubahan kebujakan secara nasional dengan asumsi bahwa tingkat pertumbuhan ekonomi Kabupaten Tanjung Jabung Barat oleh ketiga sektor unggulan tersebut selama periode 2011-2015 tumbuh lebih cepat dibandingkan tingkat pertumbuhan ekonomi nasional rata-rata. Dan apabila terjadi perubahan kebijakan pada skala nasional maka kontribusi ketiga sektor unggulan tersebut akan mengalami perubahan. Namun sebaliknya, apabila tidak terjadi perubahan pergeseran dalam skala nasional maka kontribusi ketiga sektor unggulan tersebut tetap.

Pergeseran yang terjadi selanjutnya dipengaruhi oleh komponen proportional shift (P) atau yang lebih dikenal sebagai komponen struktural (industri mix) dengan mengukur besarnya nilai shift regional netto yang diakibatkan oleh komposisi dari ketiga sektor unggulan Kabupaten Tanjung Jabung Barat. Tercatat dalam kurun waktu lima tahun yakni 2011-2015, komposisi shift regional netto dari ketiga sektor tersebut sebesar -295,710.45 (jutaan rupiah) yang berarti bahwa ketiga sektor unggulan Kabupaten Tanjung Jabung Barat periode 2011-2015 mengalami pertumbuhan yang lambat $(\mathrm{P}<0)$ di tingkat daerah. Kejadian tersebut dinilai timpang karenan pada penghitungan skala nasional ketiga sektor ekonomi tersebut petumbuhannya cepat, namun pada tingkat pertumbuhan ekonomi daerah dinilai lamban dan bahkan sedang mengalami penurunan.

Pergeseran yang terakhir yakni dipengaruhi oleh komponen differential shift (D) yang biasa disebut komponen lokasional (regional) yang mengukur besaran dari shift regional netto yang diakibatkan oleh ketiga sektor unggulan Kabupaten Tanjung Jabung Barat dalam periode 2011-2015. Pada periode tesebut dalam penghitungan komponen differential shiftnya, shift regional netto yang diakibatkan oleh ketiga sektor unggulan Kabupaten Tanjung Jabung Barat tersebut tercatat sebesar -34,748.42 (jutaan rupiah) dengan artian bahwa ketiga sektor tersebut tumbuh lebih lambat di Kabupaten Tanjung Jabung Barat dibandingkan pada tingkat nasional yang disebabkan oleh faktor-faktor lokasional interen seperti kurangnya ketersediaan bahan baku daerah, ketersediaan tenaga kerja yang minim, jarak kedaerah pemasaran yang kurang terfasilitasi oleh kendala infrastruktur daerah dan macam-macam kendala lainnya. Oleh sebab itu ketiga sektor unggulan Kabupaten Tanjung Jabung Barat pada periode 2011-2015 tidak dapat bersaing dengan baik apabila dibandingkan dengan wilayah lainnya di Provinsi Jambi $(\mathrm{D}<0)$. Maka hasil penghitungan pergeserannya sebagai beriku :

$$
\begin{aligned}
& \Delta \mathrm{E}_{\mathrm{r}, \mathrm{i}}=(\mathrm{Ns}+\mathrm{P}+\mathrm{D}) \\
& =3,851,361.79+(-295,710.45)+(-34,748.42) \\
& =3,520,902.92 \text { jutaan rupiah) }
\end{aligned}
$$

Berdasarkan penghitungan di atas, pergeseran yang terjadi selama periode 20112015 di Kabupaten Tanjung Jabung Barat yang disebabkan oleh ketiga sektor unggulan daerah tersebut yaitu sebesar 3,520,902.92 (jutaan rupiah). Pergeserasn tersebut juga berpengaruh terhadap perubahan struktur ekonomi di Kabupaten Tanjung Jabung Barat periode 2011-2015 dan berkaitan dengan perubahan pertumbuhan ekonomi di Provinsi Jambi. Namun ketiga sektor unggulan tersebut belum sepenuhnya mampu mengangkat pertumbuhan ekonomi daerah. Dengan bantuan dari beberapa tenaga ahli dalam menanggulangi permasalahan yang timbul agar dapat menjadikan ketiga sektor unggulan tersebut menjadi sektor yang memiliki keunggulan komperatif dan perlu dipacu tingkat pertumbuhannya di masa yang akan datang. 


\section{Kontribusi ketiga sektor unggulan Kabupaten Tanjung Jabung Barat bagi pertumbuhan ekonomi daerah selama periode 2011-2015}

Dalam rangka membangun suatu daerah, pemerintah daerah harus memiliki suatu pola kebijakan yang terarah terhadap tujuan pembangunan daerah dengan menekankan peningkatan pertumbuhan ekonomi daerah tersebut. Tingkat pertumbuhan ekonomi tersebut harus selaras dengan kontribusi dari masing-masing sektor ekonomi yang ada dan berkembang di tipa-tiap daerah dalam kurun waktu tertentu. Sektor ekonomi yang biasanya berkontribusi cukup besar bagi tingkat pertumbuhan ekonomi daerah digolongkan kedalam sektor unggulan ekonomi daerah. Sektor-sektor unggulan inilah nantinya yang mampu membawa perekonomian daerah menuju kesuksesan. Namun banyak terdapat kendala dalam perkembangan sektor-sektor unggulan ekonomi daerah tersebut.

Terdapat tigabelas sektor ekonomi yang ada di Kabupaten Tanjung Jabung Barat. Sektor-sektor ekonomi tersebut dibagi menjadi tiga sektor unggulan yaitu sektor pertanian, kehutanan dan perikanan, sektor penggalian dan pertambangan, dan sektor industri pengolahan. Ketiga sektor unggulan tersebut dinilai berkonstribusi besar bagi pertumbuhan ekonomi Kabupaten Tanjung Jabung Barat dalam kurun waktu lima tahun yakni 2011-2015. Nilai dari kontribusi ketiga sektor tersebut diukur melalui alat analisis tipologi klassen dengan mengklompokkannya dalam empat kuadran ekonomi melalui perbandingan sektor-sektor ekonomi yang sama di Provinsi Jambi sebagai bahan acuannya.

Tabel 4. Kontribusi sektor pertanian, perikanan, dan kehutanan, sektor pertambangan dan penggalian, dan sektor industri pengolahan Provinsi Jambi tahun 20112015 bagi pertumbuhan ekonomi daerah

\begin{tabular}{|c|c|c|c|c|}
\hline \multirow{3}{*}{ Sektor } & \multicolumn{4}{|c|}{$\begin{array}{c}\text { Provinsi Jambi } \\
\text { (Milyaran Rupiah) }\end{array}$} \\
\hline & \multicolumn{2}{|c|}{ Tahun } & \multirow{2}{*}{$\begin{array}{c}\text { Rata rata } \\
\text { Pertumbuhan } \\
\text { (g) } \\
\%\end{array}$} & \multirow{2}{*}{$\begin{array}{c}\text { Rata Rata } \\
\text { Kontribusi } \\
(\mathrm{s}) \\
\%\end{array}$} \\
\hline & 2011 & 2015 & & \\
\hline $\begin{array}{l}\text { Pertanian, Perikanan dan } \\
\text { Kehutanan }\end{array}$ & $24,744.9$ & $32,815.9$ & 8.15 & 25.83 \\
\hline Pertambangan dan Penggalian & $27,265.3$ & $30,879.9$ & 3.31 & 26.09 \\
\hline Industri Pengolahan & $11,217.1$ & $13,948.8$ & 6.08 & 11.29 \\
\hline Jumlah & $63,227.3$ & $77,644.6$ & 5.70 & 63.21 \\
\hline Total PDRB & $97,740.9$ & $\begin{array}{c}125,038 \\
7\end{array}$ & 6.98 & 100.00 \\
\hline
\end{tabular}

Sumber: BPS Provinsi Jambi, 2016 (data diolah)

Berdasarkan data produk domestik regional bruto (PDRB) tabel 4 di atas yang digunakan untuk menunjukkan bahwa kontribusi dari ketiga sektor perekonomian yang ada di Provinsi Jambi tahun 2011-2015 yang digunakan sebagai bahan acuan perbandingan terhadap ketiga sektor unggulan Kabupaten Tanjung Jabung Barat tahun 2011-2015 guna menentukan pengklasifikasian ketiga sektor unggulan tersebut kedalam beberapa kuadran menurut tipologi klassen. Hasil penghitungan tersebut dapat dilihat pada tabel di bawah ini : 
Tabel 5. Kontibusi sektor unggulan Kabupaten Tanjung Jabung Barat tahun 2011-2015 bagi pertumbuhan daerah

\begin{tabular}{|c|c|c|c|c|c|}
\hline \multirow{3}{*}{ Sektor } & \multicolumn{4}{|c|}{$\begin{array}{c}\text { Kabupaten Tanjung Jabung Barat } \\
\text { (Jutaan Rupiah) }\end{array}$} & \multirow[t]{3}{*}{$\begin{array}{c}\text { Kuadr } \\
\text { an }\end{array}$} \\
\hline & \multicolumn{2}{|c|}{ Tahun } & $\begin{array}{c}\text { Rata Rata } \\
\text { Pertumbuhan (oi) }\end{array}$ & $\begin{array}{c}\text { Rata Rata } \\
\text { Kontribusi (si) }\end{array}$ & \\
\hline & 2011 & 2015 & $\%$ & $\%$ & \\
\hline $\begin{array}{l}\text { Pertanian, } \\
\text { Perikanan dan } \\
\text { Kehutanan }\end{array}$ & $3,945,664.69$ & $5,431,857.89$ & 9.41 & 20.27 & III \\
\hline $\begin{array}{l}\text { Pertambangan } \\
\text { dan Penggalian }\end{array}$ & $9,525,161.45$ & $10,826,626.48$ & 3.41 & 44.01 & I \\
\hline $\begin{array}{l}\text { Industri } \\
\text { Pengolahan }\end{array}$ & $4,293,757.57$ & $5,027,002.18$ & 4.26 & 20.15 & II \\
\hline Jumlah & $17,491,583.70$ & $21,285,486.60$ & 5.42 & 84.43 & \\
\hline Total PDRB & $20,794,458.62$ & $25,446,121.48$ & 5.59 & 100.00 & \\
\hline
\end{tabular}

Berdasarkan tabel 5 di atas, tercatat pada tahun 2011 total PDRB ketiga sektor unggulan Kabupaten Tanjung Jabung Barat sebesar 17,491,583.70 (jutaan rupiah) dari total PDRB sebesar 20,794,458.62 (jutaan rupiah) dan meningkat pada tahun 2015 sebesar 21,258,486.60 (jutaan rupiah) dari total PDRB sebesar 25,446,121.48 (jutaan rupiah) dengan rata-rata pertumbuhannya sebesar 5.59 persen. Peningkatan tersebut tidak lepas dari kontribusi ketiga sektor unggulan Kabupaten Tanjung Jabung Barat yang sebesar 84.43 persen dari total kontribusi ke tigabelas sektor ekonomi yang ada di Kabupaten Tanjung Jabung Barat. Rincian rata-rata kontribusi ketiga sektor unggulan tersebut selama periode 2011-2015 yaitu sektor pertanian, perikanan dan kehutanan sebesar 20.27 persen, sektor pertambangan dan penggalian sebesar 44.01 persen dan sektor industri pengolahan sebesar 20.15 persen.

Berdasarkan keterangan di atas, pengklasifikasian ketiga sektor unggulan Kabupaten Tanjung Jabung Barat dengan bahan acuan sektor-sektor ekonomi yang sama di Provinsi Jambi selama periode 2011-2015 dapat dilihat pada tabel di bawah ini:

Tabel 6. Klasifikasi sektor unggulan Kabupaten Tanjung Jabung Barat tahun 2011-2015

\begin{tabular}{ccc}
\hline Kontribusi & \multicolumn{2}{c}{ Pertumbuhan sektoral } \\
\cline { 2 - 3 } sektoral & $\mathbf{g}_{\mathbf{i}} \geq \mathbf{g}$ & $\mathbf{g}_{\mathbf{i}} \leq \mathbf{g}$ \\
\hline $\mathrm{s}_{\mathrm{i}} \geq \mathrm{s}$ & Pertambangan dan Penggalian & Sektor Industri Pengolahan \\
$\mathrm{s}_{\mathrm{i}} \leq \mathrm{s}$ & $\begin{array}{c}\text { Sektor Pertanian, Kehutanan, dan } \\
\text { Perikanan }\end{array}$ & --- \\
\hline
\end{tabular}

Sumber : Junaidi Chaniago (blog), 2010

Berdasarkan pengklasifikasian ketiga sektor unggulan Kabupaten Tanjung Jabung Barat periode 2011-2015 pada tabel 6 di atas menunjukkan bahwa sektor pertambangan dan penggalian digolongkan ke dalam kuadran I dengan arti bahwa sektor tersebut menjadi sektor yang maju dan tumbuh dengan cepat dibandingkan sektor ekonomi yang sama di Provinsi Jambi . Perbandingan tersebut menunjukan bahwa sektor pertambangan dan penggalian Kabupaten Tanjung Jabung Barat tahun 2011-2015 memiliki rata-rata pertumbuhan ekonomi $\left(\mathrm{g}_{\mathrm{i}}\right)$ tiap tahunnya lebih tinggi yakni sebesar 3.41 persen dibandingkan dengan rata-rata pertumbuhan ekonomi (g) tiap tahunnya bagi sektor pertambangan dan penggalian di Provinsi Jambi yang sebesar 3.31 persen. Begitupun dengan rata-rata kontribusi $\left(\mathrm{s}_{\mathrm{i}}\right)$ sektor pertambangan dan penggalian Kabupaten Tanjung Jabung Barat tahun 2011-2015 sebesar 44.01 persen. Jumlah tersebut lebih besar dibandingkan rata-rata kontribusi (s) sektor pertambangan dan penggalian di Provinsi Jambi pada tahun 2011-2015 yang sebesar 26.09 persen. Dengan kata lain, sektor 
pertambangan dan penggalian di Kabupaten Tanjung Jabung Barat tahun 2011-2015 memiliki kinerja laju pertumbuhan ekonomi dan pangsa yang lebih besar dibandingkan dengan sektor petambangan dan penggalian di Provinsi Jambi pada tahun yang sama yakni tahun 2011-2015.

Selanjutnya untuk sektor unggulan Kabupaten Tanjung Jabung Barat tahun 20112015 yang digolongkan kedalam kudaran II oleh klasifikasi tipologi klassen yang berarti sektor unggulan tersebut menjadi sektor yang maju namun terketan ialah sektor industri pengolahan. Sektor industri pengolahan Kabupaten Tanjung Jabung Barat tahun 20112015 memiliki rata-rata pertumbuhan ekonomi $\left(\mathrm{g}_{\mathrm{i}}\right)$ yang lebih rendah dibandingkan ratarata petumbuhan ekonomi (g) sektor industri pengolahan di Provinsi Jambi. Komposisi perbandingan nilai rata-rata pertumbuhan ekonomi sektor industri pengolahan tersebut sebesar 4.26 persen $\leq 6.08$ persen dalam kurun waktu lima tahun. Namun, sektor industri pengolahan di Kabupaten Tanjung Jabung Barat tahun 2011-2015 memiliki nilai rata-rata kontribusi ( $\mathrm{s}_{\mathrm{i}}$ ) yang lebih tinggi terhadap tingkat pertumbuhan ekonomi daerah yakni sebesar 20.15 persen dibandingan dengan nilai rata-rata kontribusi (s) sektor industri pengolahan di Provinsi Jambi tahun 2011-2015 sebesar terhadap 11.29 persen. Hal ini mengidentifikasikan bahwa sektor industri pengolahan di Kabupaten Tanjung Jabung Barat dapat dikategorikan sebagai sektor ekonomi unggulan yang telah jenuh terhadap tingkat pertumbuhan ekonomi daerah pada kurun waktu 2011-2015.

Sektor pertanian, kehutana dan perikanan merupakan sektor unggulan Kabupaten Tanjung Barat tahun 2011-2015 yang masuk dalam kuadran III oleh klasifikasi tipologi klassen. Penggolongan tersebut memberi arti bahwa sektor pertanian, kehutanan dan perikanan merupakan sektor yang memiliki tingkat potensi tinggi (potensial) dan masih dapat berkembang dengan pesat. Pada periode 2011-2015, rata-rata pertumbuhan ( $\mathrm{g}$ i) sektor unggulan Kabupaten Tanjung Jabung Barat tersebut sebesar 9.41 persen. Nilai tersebut dianggap lebih tinggi dibandingkan rata-rata pertumbuhan $(\mathrm{g})$ sektor pertanian, kehutanan dan perikanan di Provinsi Jambi yang berjumlah 8.15 persen. Tetapi, rata-rata kontribusi $\left(\mathrm{s}_{\mathrm{i}}\right.$ ) dari sektor pertanian, kehutanan dan perikanan tersebut lebih rendah yakni sebasar 20.27 persen dibandingkan dari rata-rata kontribusi (s) sektor pertanian, kehutanan dan perikanan di Provinsi Jambi tahun 2011-2015 yang berjumlah 25.83 persen terhadap tingkat pertumbuhan ekonomi daerah. Hal tersebut menjelaskan bahwa sektor pertanian, kehutanan dan perikanan Kabupaten Tanjung Jabung Barat tahun 20112015 merupakan sektor yang sedang hangat (booming) terhadap tingkat pertumbuhan ekonomi daerahnya meskipun pangsa pasar daerah tersebut relatif lebih kecil dibandingkan rata-rata nasional.

Secara umum, hasil analisis di atas menunjukan bahwa kontribusi dari ketiga sektor unggulan Kabupaten Tanjung Jabung Barat selama periode 2011-2015 memiliki tren yang positif terhadap tingkat pertumbuhan ekonomi daerah. Hasilnya selain mampu memenuhi kebutuhan dalam wilayah, ketiga sektor unggulan tersebut juga mampu bersaing pada tingkat nasional di Provinsi Jambi dan bahkan mampu untuk bersaing di kanca nasional.

\section{KESIMPULAN DAN SARAN}

\section{Kesimpulan}

Berdasarkan hasil analisis data, pergeseran ketiga sektor unggulan ekonomi Kabupaten Tanjung Jabung Barat tahun 2011-2015 dengan menggunakan analisis ShiftShare mengalami perubahan pada tingkat nasional (Ns) sebesar 3,851,361.79, dengan nilai differential shift (D) sebesar -34,748.82 (jutaan rupiah) dan nilai proportional shift (P) sebesar -295,710.45 (jutaan rupiah), dimana nilai pergeseran ketiga sektor unggulan tersebut mengalami perkembangan dalam kurun waktu 2011-2015 sebesar 3,520,902.92 (jutaan rupiah). 
Ketiga sektor unggulan tersebut diklasifikasikan kedalam analisis Tipologi Klassen guna mengetahui nilai kontribusinya terhadap tingkat pertumbuhan daerah, dimana sektor pertambangan dan penggalian menjadi kuadran I, sektor industri pengolahan menjadi kuadran II, dan sektor pertanian, kehutanan dan perikanan menjadi kuadran III.

\section{Saran}

Pemerintah sebaiknya harus terus mendorong perkembangan ketiga sektor unggulan tersebut mengingat ketiga sektor unggulan tersebut masihlah memiliki beberapa ketidak unggulan yakni secara lokasional dan kompetitif. Ketersediaan sumber daya, teknologi dan iklim usaha yang kondusif menjadi syarat mutlak disamping peran infrastruktur yang kini tengah ditingkatkan pemerintah dalam mengoptimalkan peran dari ketiga sektor unggulan ini. Kebijakkan ekonomi yang variatif dan aplikatif harus diwujudkan agar ketiga sektor unggulan tersebut mampu berkembang dan dapat mengangkat tingkat kesejahteraan daerah dan juga haruslah memperhatikan sektor-sektor ekonomi lainnya yang belum berada pada peran yang optimal.

Peran pemerintah dalam penanggulan masalah tersebut sangatlah diharapkan guna dalam peningkatan kontribusi terhadap pertumbuhan daerah. Pemerintah daerah juga harus memberikan dana alokasi yang lebih untuk membangun sarana dan prasarana yang menunjang perkembangan dari ketiga sektor unggulan tersebut juga memperhatikan kesiapan faktor-faktor pendukung seperti sumber daya alam dan sumber daya manusia yang ada, namun perhatian tersebut juga tidak terlepas terhadap peningkatan sektor-sektor ekonomi non basis agar mobilitas perekonomian Kabupaten Tanjung Jabung Barat kedepannya dapat berjalan dengan lancar.

\section{DAFTAR PUSTAKA}

Adisasmita, R. (2008). Pengembangan wilayah: konsep dan teori. Graha Ilmu: Yogyakarta.

Alamsyah, Z. (2016).Perkembangan ekonomi Kabupaten Tanjung Jabung Barat 2011 2015 : Tinjauan secara makro. Seminar. Disampaikan pada sosialisasi sensus ekonomi tahun 2016 BPS Kabupaten Tanjung Jabung Barat, 12 Desember 2015. https://zalamsyah.files.wordpress.com/. diakses pada 21 November 2017.

Arsyad, L. (1999).Pengantar perencanaan dan pembangunan ekonomi daerah. BPFE: Yogyakarta.

Chaniago, J. (2010).Mengenal tipologi klassen (Seri 1. Analisis ekonomi daerah).https://junaidichaniago.wordpress.com/2010/02/14/mengenaltipologikla ssen-seri-1-analisis-ekonomi-daerah/. diakses pada 22 April 2018.

Kuncoro, M. (2000).Ekonomi Pembangunan. YKPN: Yogyakarta.

Munir, B. (2002).Perencanaan pembangunan daerah dalam perspektif otonomi daerah:Cetakan ke-2. Bappeda Propinsi NTB: Mataram.

P Parmadi, E Emilia, Z Zulgani.(2018). Daya saing produk unggulan sektor pertanian Indonesia dalam hubungannya dengan pertumbuhan Ekonomi, Jurnal Paradigma Ekonomika 13 (2), 77-86

R Rosita, H Haryadi, A Amril. (2014).Determinan Ekspor CPO Indonesia, Jurnal Perspektif Pembiayaan dan Pembangunan Daerah 1 (4), 183-183

Sirojuzilam., dan Mahalli, K. (2010).Pembangunan dan perencanaan ekonomi regional. USU Press: Medan.

Sukirno, S. (2006).Pengantar Teori mikro ekonomi : Edisis ketiga. PT. Raja Grafindo Persada: Jakarta.

Tarigan, R. (2005).Ekonomi regional, teori dan aplikasi : Edisi revisi. PT Bumi Angkasa: Jakarta. 